\title{
An exploratory trial of parental advice for increasing vegetable acceptance in infancy
}

\author{
Alison Fildes ${ }^{1}$, Carla Lopes ${ }^{2,3}$, Pedro Moreira ${ }^{3,4}$, George Moschonis ${ }^{5}$, Andreia Oliveira ${ }^{2,3}$, \\ Christina Mavrogianni ${ }^{5}$, Yannis Manios ${ }^{5}$, Rebecca Beeken ${ }^{1}$, Jane Wardle ${ }^{1}$ and Lucy Cooke ${ }^{1 *}$ \\ ${ }^{1}$ Department of Epidemiology and Public Health, Health Behaviour Research Centre, University College London, \\ Gower Street, London WC1E 6BT, UK \\ ${ }^{2}$ Department of Clinical Epidemiology, Predictive Medicine and Public Health, University of Porto Medical School, \\ Porto, Portugal \\ ${ }^{3}$ Institute of Public Health, University of Porto, Porto, Portugal \\ ${ }^{4}$ Faculty of Nutrition and Food Sciences, University of Porto, Porto, Portugal \\ ${ }^{5}$ Department of Nutrition and Dietetics, Harokopio University of Athens, 70 El. Venizelou, Kallithea 17671, Athens, Greece \\ (Submitted 26 August 2014 - Final revision received 18 December 2014 - Accepted 16 April 2015-First published online 11 June 2015)
}

\begin{abstract}
Research suggests that repeatedly offering infants a variety of vegetables during weaning increases vegetable intake and liking. The effect may extend to novel foods. The present study aimed to investigate the impact of advising parents to introduce a variety of single vegetables as first foods on infants' subsequent acceptance of a novel vegetable. Mothers of 4- to 6-month-old infants in the UK, Greece and Portugal were randomised to either an intervention group $(n 75)$, who received guidance on introducing five vegetables (one per d) as first foods repeated over $15 \mathrm{~d}$, or a control group $(n 71)$ who received country-specific 'usual care'. Infant's consumption $(\mathrm{g})$ and liking (maternal and researcher rated) of an unfamiliar vegetable were assessed 1 month post-intervention. Primary analyses were conducted for the full sample with secondary analyses conducted separately by country. No significant effect of the intervention was found for vegetable intake in the three countries combined. However, sub-group analyses showed that UK intervention infants consumed significantly more novel vegetable than control infants (32.8 (SD 23.6) $v$. 16.5 (SD 12.1) g; $P=0.003$ ). UK mothers and researchers rated infants' vegetable liking higher in the intervention than in control condition. In Portugal and Greece, there was no significant intervention effect on infants' vegetable intake or liking. The differing outcome between countries possibly reflects cultural variations in existing weaning practices. However, the UK results suggest in countries where vegetables are not common first foods, advice on introducing a variety of vegetables early in weaning may be beneficial for increasing vegetable acceptance.
\end{abstract}

Key words: Vegetables: Weaning: Infancy: Food preferences: Children: Exposure

An important predictor of children's fruit and vegetable consumption is their enjoyment of these foods ${ }^{(1,2)}$. Innate preferences for sweet tastes and dislike of sour or bitter tastes mean that fruit is readily accepted, but that liking for vegetables may be harder to achieve. However, innate preferences can be modified through pre- and post-natal experiences ${ }^{(3)}$. Flavours become more acceptable as they grow in familiarity and there is unequivocal evidence in young children that intake and liking for unfamiliar foods can be increased through repeated exposure, i.e. providing repeated opportunities to taste small quantities of the food ${ }^{(4-10)}$.

Between the ages of 4 and 7 months, infants are highly receptive to new flavours and textures, requiring fewer exposures than older children to increase acceptance ${ }^{(11-14)}$. Exposing children to the taste of commonly rejected foods, such as vegetables, may be most effective in early infancy before the onset of food neophobia or pickiness (a normal developmental stage during the second year of life) ${ }^{(14)}$. Since food preferences develop early and have been shown to track through later childhood and into adulthood ${ }^{(15,16)}$, early intervention is likely to reap the greatest benefit.

While repeated exposure to a single vegetable flavour increases infants' acceptance, the speed with which they acquire preferences means that a lack of sufficient variety might result in a 'monotony' effect - the infant becoming bored with the taste ${ }^{(17)}$. Daily changes in the vegetables offered to infants during the transition to solid foods have been shown to lead to immediate increases in preference and intake, and a generalisation of the effect to acceptance of novel tastes ${ }^{(17-19)}$. In a group of formula-fed infants, the 
effect of offering a variety of different vegetables $v$. carrots alone, or potatoes alone over a period of $9 \mathrm{~d}$ was evaluated $^{(17)}$. Infants in both the variety and carrot groups significantly increased their intake of carrots compared with infants fed potatoes, but only the infants exposed to a variety of tastes ate more of a novel food at the end of the exposure period. It has been suggested that the variety of vegetables from meal to meal offered to weaning infants is more important than the overall number of vegetables offered. For example, increased intake of novel foods was observed in weaning-age infants experiencing daily changes in the vegetables offered compared to infants fed three vegetables, each for three consecutive days ${ }^{(18)}$, suggesting that the beneficial effect of variety is maximised by daily changes. In addition, a more varied diet during the weaning period has been linked to greater dietary diversity in later childhood $^{(20,21)}$.

The benefits of repeated and varied exposure early in the complementary feeding period have been previously described $^{(18,19,22,23)}$, suggesting promising opportunities for increasing children's vegetable intake. However, no studies to date have tested the procedures in the form of an easily disseminable intervention comprising simple, practical guidance to parents for introducing a variety of vegetables as first foods. Furthermore, no previous study of variety exposure in infants has included a no-treatment control group in which mothers receive only the current standard weaning advice offered by their national health service. Finally, although the existing weaning recommendations and practices vary across Europe, no study to date has examined crosscultural differences in the effectiveness of such an intervention.

The present study is an exploratory trial of an intervention comprising guidance to parents on the introduction of a variety of vegetables at the first stages of weaning. The primary outcome was infants' consumption of a novel vegetable, offered 1 month after the start of complementary feeding. The secondary outcome was infant's 'liking' for the novel vegetable, rated by both researchers and mothers. The same procedure was followed by researchers in the UK, Greece and Portugal in order to examine the effect of the intervention compared with usual care in the different countries.

\section{Subjects and methods}

\section{Trial design}

A multi-centre, individually randomised (ratio; 1:1), parallelgroup study design was adopted for this exploratory trial conducted in the UK, Greece and Portugal between February 2011 and July 2012.

\section{Sample size}

Estimating effect size was difficult because few comparable studies have been published. The closest study in the literature $^{(17)}$ achieved an extremely large effect on vegetable intake $(d=4.0)$ from a brief but intensive exposure-based intervention, with outcomes measured in the laboratory. A second parent-led, exposure-based intervention with 2- to 6-year-olds showed a significant, but smaller effect $(d=0 \cdot 2)$ on children's vegetable consumption ${ }^{(4)}$. Outcomes in previous studies have therefore ranged from small to very large, with larger effects in a younger age group, which is most comparable to the present study. The sample size for the current trial ( $n$ 120) was therefore designed to provide $80 \%$ power to detect a medium effect size $(d=0.5)$ at $P=0.05^{(24)}$ on intake of a novel vegetable in a taste test.

\section{Recruitment of participants}

Women in the final trimester of their pregnancy and mothers of infants aged less than 6 months were recruited from antenatal clinics ( $n$ 327), primary care, paediatricians and hospitals in London (UK), Athens (Greece) and Porto (Portugal) to a larger study exploring children's fruit and vegetable acceptance during weaning. Mothers were eligible to participate if they were over 18 years old at recruitment, they were sufficiently proficient in each country's respective native language to understand the study materials and their infant was born after 37 weeks' gestation, without diagnosed feeding problems. Mothers who volunteered to participate were asked to complete a consent form and baseline questionnaire following recruitment. A sub-sample of these participants was randomly selected to take part in the present trial and invited to meet with a researcher or health professional immediately prior to the initiation of complementary feeding. All participants were advised that they were free to withdraw from the study at any point. The flow of participants through the trial in each of the three countries is illustrated in Fig. 1.

\section{Randomisation}

An independent statistician at University College London generated a block randomisation matrix that was used in all three countries. Individual participants were randomly assigned to an intervention or control ('usual care') condition following an initial interview to establish the feeding method. As research has shown that breast-fed infants accept new foods more readily than their formula-fed counterparts ${ }^{(25,26)}$, equal representation of breast-fed and formula-fed infants were ensured across the groups, and within each country, using block randomisation. Allocation was revealed to the researcher. Because of the nature of the intervention, parents in the intervention arm and researchers delivering the intervention were not blind. However, parents were unaware of the randomised controlled design and therefore neither the control nor the intervention group knew of the existence of the other.

\section{Ethical approval}

This study was conducted according to the guidelines laid down in the Declaration of Helsinki and all procedures involving human subjects/patients were approved by the relevant ethical committees in each participating country. In the UK, 


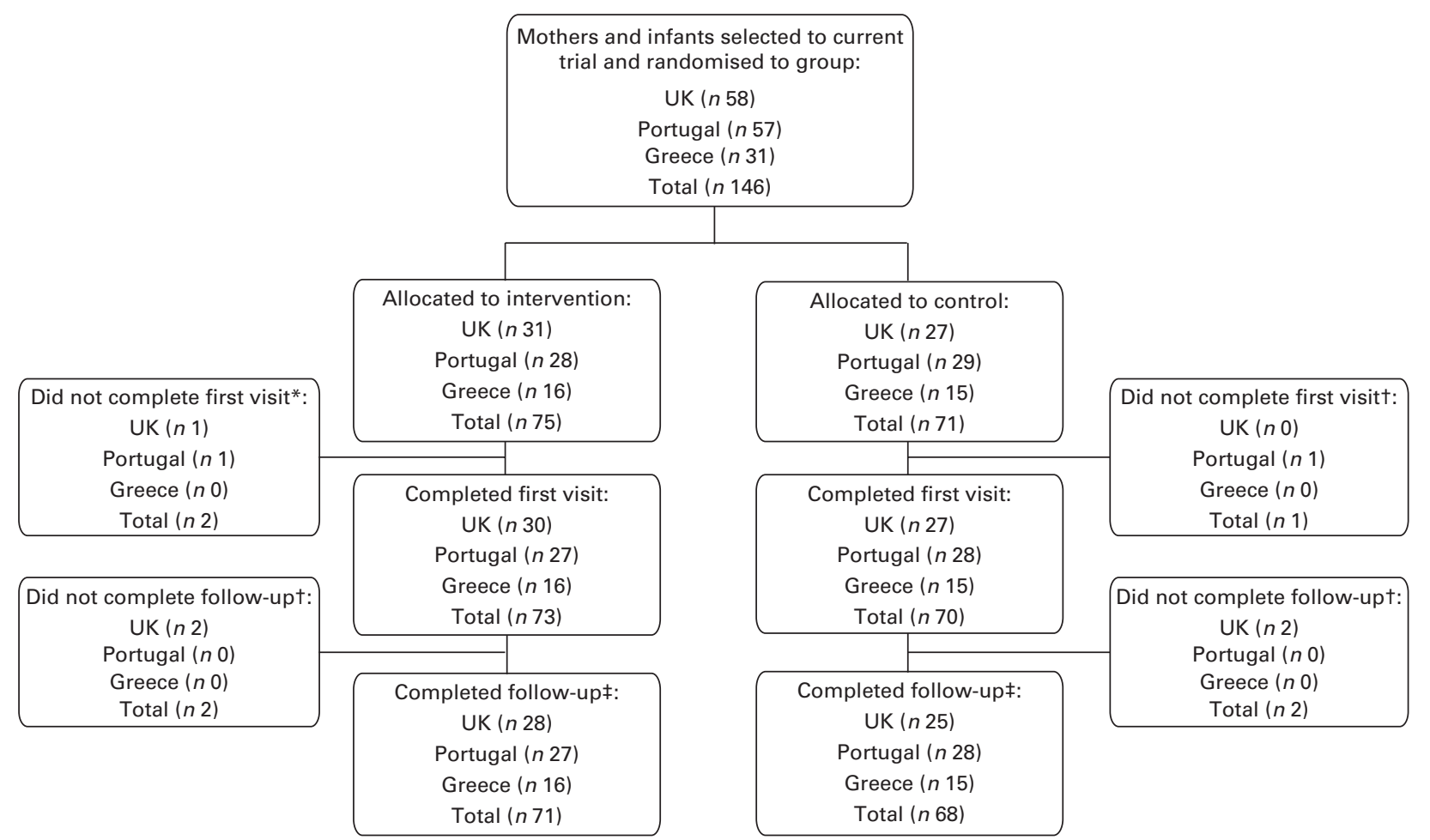

Fig. 1. Flow of participants through the study. ${ }^{*}$ Reasons for lost to follow-up following randomisation: in the UK intervention group, family non-contactable ( $n$ 1); in Portugal, intervention group family withdrew from study $(n 1)$; in Portugal, control group family unavailable for visit $(n 1)$. † Reasons for lost to follow-up following first visit: in the UK intervention group, baby was unwell so unable to complete taste test $(n 1)$ and family unavailable for visit ( $n 1)$; in the UK control group, family unavailable for visit $(n 1)$, family withdrew from study $(n 1)$. $\ddagger$ Families that completed the taste test (the primary outcome).

ethical approval was granted by the NHS Central London Research Ethics Committee (10/H0718/54), research and development approval by NHS University College Hospital and NHS North Central London Research Consortium. In Greece, ethical approval was granted by the Ethical Committee of Harokopio University of Athens (session no. 27/14-07-2010). In Portugal, ethical approval was granted by the local ethical committee (Ethical committee for Health of the São João Hospital/University of Porto Medical School - 29.JUL10-12951). Written informed consent was obtained from the subjects. In the UK, this trial is registered as ISRCTN85048101.

\section{Intervention}

All participants met with a researcher or health professional immediately prior to the initiation of complementary feeding (i.e. introducing solid foods). Visits took place either at the participants' home or at a paediatrician's office and the mothers determined the precise timing of these visits (which in some instances was up to 4 weeks prior to the initiation of complementary feeding).

In the intervention group, a researcher or health professional explained to the participant: (1) the importance of introducing vegetables early in the weaning process, (2) the beneficial effects of offering different single vegetables each day, (3) the techniques of exposure feeding, (4) interpreting infants' facial reactions to food and (5) the need for persistence when an infant initially rejects a food. A leaflet reinforcing these messages (standardised across countries) was given to participants, who were then asked to complete a short questionnaire about their infant's early milk-feeding experiences.

In consultation with mothers (and paediatricians in the Portuguese sample), five vegetables were selected as the first foods to be introduced. Mothers were provided with a small number of commercially available vegetable purées to use, but were told that they could prepare their own foods if they preferred. They were asked to offer the five vegetables in a sequence over $15 \mathrm{~d}$ as follows: A,B,C,D,E, A,B,C,D,E, $\mathrm{A}, \mathrm{B}, \mathrm{C}, \mathrm{D}, \mathrm{E}$ and to record progress on a chart provided. For a further $5 \mathrm{~d}$, participants were told to continue to offer vegetables, but in addition, to start to introduce additional age-appropriate foods.

Participants in the control group completed the same questionnaire as intervention mothers. However, control mothers were not offered any specific guidance, instructions or information on weaning with vegetables. Instead, the control group received 'usual care', which varies between European countries.

In the UK, the recommendations are to introduce fruits, vegetables and baby rice or cereal as first foods, but the information provided to mothers is inconsistent and the advice available may vary by local health authority. In Greece, paediatricians provide parents with guidance on appropriate first foods, commonly baby rice, cereals or fruits. In Portugal, the guidelines for weaning are not prescriptive, and health professionals are advised to adapt international and national 
recommendations (e.g. from WHO, ESPGHAN and Portuguese Paediatric Society), to the needs and circumstances of individual infants ${ }^{(27)}$. In Portugal there has been a move towards advice to introduce vegetable soups or purées as first foods.

\section{Outcome measures}

Mothers in both control and intervention groups completed questionnaires about themselves and their infant prior to the intervention and at follow-up ( 1 month after the introduction of solid foods), which included items on demographics and feeding practices. Mothers reported their date of birth, parity, marital status and educational qualifications. Mothers reported separately on the frequency of fruit and vegetable servings they had consumed in the past week and the data were recoded to provide an estimation of the total number each of fruit and vegetable portions consumed daily. Selfreported height and weight was used to calculate maternal BMI $\left(\mathrm{kg} / \mathrm{m}^{2}\right)$ and maternal age was calculated at the time of child's birth. Maternal age and BMI were treated as continuous variables, while education was dichotomised as 'university level' $v$. 'below university level'. Mothers were also asked to record their child's date of birth, sex, birth weight (in $\mathrm{kg}$ ) and the number of weeks' gestation at birth, to provide an estimate of gestational age. Feeding method was assessed with the question, 'Which feeding methods did you use in the first three months', with response options: 'entirely breastfeeding'; 'mostly breastfeeding with some bottle-feeding'; 'equally breastfeeding and bottle-feeding'; 'mostly bottle-feeding and some breastfeeding'; 'almost entirely bottle-feeding (only tried breastfeeding a few times)'; 'entirely bottle-feeding (never tried breastfeeding)'; and 'other'. Infant age at the time of introduction to solids was calculated in weeks by using the child's date of birth and the date on which mothers reported that they had offered solid food for the first time.

At follow-up, taste tests were administered in which an unfamiliar vegetable (artichoke purée) was offered to participating infants. The primary outcome was intake $(\mathrm{g})$ of the novel vegetable. Infant liking for the vegetable (independently rated by mothers and researchers) was also recorded. The procedure was then repeated with a novel fruit (peach purée), which acted as a control food and to provide an indication of whether the intervention had the unintended side effect of reducing acceptance of foods other than vegetables.

Taste tests took place in the infant's home or paediatrician's office and test foods were fed to infants by mothers in the presence of the researcher. The researcher present at the taste test was the same individual who delivered the intervention and was not therefore able to be blinded to condition. Taste tests were conducted at the child's mealtime in order to ensure they were hungry. Mothers were provided with two $130 \mathrm{~g}$ jars of artichoke purée, the contents of which were weighed prior to the start of the taste test. Artichoke purée was selected on the basis that it is an unfamiliar and rarely consumed vegetable among young children across Europe $^{(8,28)}$ and not available as a commercial baby food in any of the three participating countries. Mothers were instructed to feed their infant as normal and at their usual pace until the infant refused the food on three or more occasions, or had finished two full jars. Refusal was defined as keeping the mouth closed, turning the head away, pushing the spoon away, crying, or playing ${ }^{(19)}$. Conditions were kept as naturalistic as possible; with mothers using any techniques (i.e. facial expressions and verbal encouragements) they would normally employ to encourage their infant to eat in a mealtime situation. On completion of the test, all spilled food was returned to the bowl/jar, which was weighed again to calculate the weight of food consumed ${ }^{(19)}$. Immediately after each feeding session, the mother and researcher separately and independently rated the infant's apparent liking for the food on a 9-point scale, ranging from $1=$ 'dislikes very much', to $9=$ 'likes very much' with a central point of $5=$ 'neither likes nor dislikes ${ }^{,(22,29)}$. The entire process was then repeated with the unfamiliar test fruit (peach purée). The vegetable was always offered first, followed by the fruit approximately $10 \mathrm{~min}$ later.

\section{Statistical analyses}

Participants with complete data on the primary outcome (intake at the taste test) were included in the analyses. ANCOVA were conducted to compare intervention and control groups by weight of vegetable consumed, and researcher's and mother's rating of vegetable liking at the taste test while controlling for country. These analyses were repeated for fruit intake and the researcher's and mother's rating of fruit liking at the taste test. As typical weaning practices in the three participating nations varied, secondary analyses were then performed comparing intake and liking ratings between intervention and control groups for each country separately.

\section{Results}

The flow of participants through the trial is illustrated in Fig. 1. In total, 139 families completed the trial, including the taste tests 1 month post-intervention (fifty-three, thirty-one and fifty-five families in the UK, Greece and Portugal, respectively). Sample demographics are presented in Table 1. The first solid foods consumed by the infants in the three countries, provided by experimental condition, are shown in Table 2 .

Completed intervention charts were returned by $86 \%$ of intervention families (UK; $100 \%$ (28/28), Greece; $100 \%$ (16/16), Portugal; 63\% (17/27)). Completed charts revealed that over the 15-d intervention period, parents recorded their infants consuming vegetables on $89 \%$ (mean 13.3 (SD 3.0)) of the fifteen possible eating occasions (UK; (86\%) mean 12.8 (SD 3.4), Greece; (95\%), mean 14.2 (SD 1.8), Portugal $(88 \%)$, mean $13 \cdot 1(\mathrm{sD} 3 \cdot 0))$. Infants were recorded as eating nothing on $7 \%$ (mean 1.0 (SD 1.8) of the fifteen intervention days (UK; (6\%) mean 1.1 (SD 2.4), Greece; (5\%), mean 0.8 (SD 1.8), Portugal; (8\%), mean 1.2 (SD 1.7)). Data on infants' willingness to eat during the intervention period were missing for $5 \%$ of the total eating occasions (UK; $8 \%$, Greece; 0\%, Portugal; 5\%). 
Table 1. Characteristics of mothers and infants by condition and country

(Mean values and standard deviations; number of mothers and infants and percentages)

\begin{tabular}{|c|c|c|c|c|c|c|c|c|c|c|c|c|c|c|c|c|c|c|}
\hline & \multicolumn{8}{|c|}{ Control } & \multicolumn{10}{|c|}{ Intervention } \\
\hline & \multicolumn{2}{|c|}{ UK (n 25) } & \multicolumn{2}{|c|}{$\begin{array}{l}\text { Greece } \\
(n 15)\end{array}$} & \multicolumn{2}{|c|}{$\begin{array}{l}\text { Portugal } \\
(n 28)\end{array}$} & \multicolumn{2}{|c|}{$\begin{array}{c}\text { Combined } \\
(n 68)\end{array}$} & \multicolumn{2}{|c|}{ UK (n 28) } & \multicolumn{2}{|c|}{$\begin{array}{l}\text { Greece } \\
(n 16)\end{array}$} & \multicolumn{2}{|c|}{$\begin{array}{l}\text { Portugal } \\
\text { (n 27) }\end{array}$} & \multicolumn{2}{|c|}{$\begin{array}{c}\text { Combined } \\
(n 71)\end{array}$} & \multicolumn{2}{|c|}{ Total $(n$ 139) } \\
\hline & $n$ & $\%$ & $n$ & $\%$ & $n$ & $\%$ & $n$ & $\%$ & $n$ & $\%$ & $n$ & $\%$ & $n$ & $\%$ & $n$ & $\%$ & $n$ & $\%$ \\
\hline \multicolumn{19}{|l|}{ Mothers } \\
\hline \multicolumn{19}{|l|}{ Age (at child's birth, years) } \\
\hline Mean & \multicolumn{2}{|c|}{$\begin{array}{c}34 \cdot 2 \\
5.1\end{array}$} & \multicolumn{2}{|c|}{31.5} & \multicolumn{2}{|c|}{$32 \cdot 0$} & \multicolumn{2}{|c|}{$32 \cdot 7$} & \multirow{2}{*}{\multicolumn{2}{|c|}{$\begin{array}{c}34.8 \\
2.9\end{array}$}} & \multirow{2}{*}{\multicolumn{2}{|c|}{$\begin{array}{c}33 \cdot 6 \\
4.0\end{array}$}} & \multicolumn{2}{|c|}{$31 \cdot 3$} & \multicolumn{2}{|c|}{$33 \cdot 2$} & & \\
\hline SD & & & & & & & & & & & & & & & & 5 & & \\
\hline $\mathrm{BMI}\left(\mathrm{kg} / \mathrm{m}^{2}\right)$ & & & & & & & & & & & & & & & & & & \\
\hline Mean & & & & 4 & & & & & & .9 & & 3 & & .9 & & 6 & & \\
\hline SD & & & & 6 & & & & & & 2 & & 5 & & 4 & & 3 & & \\
\hline Primapara & 16 & $64 \cdot 0$ & 8 & $53 \cdot 3$ & 14 & $50 \cdot 0$ & 38 & 55.9 & 14 & $50 \cdot 0$ & 8 & $50 \cdot 0$ & 17 & $62 \cdot 9$ & 39 & 54.9 & 77 & 55.4 \\
\hline Education* & & & & & & & & & & & & & & & & & & \\
\hline Below University & 2 & 8.7 & 6 & $40 \cdot 0$ & 12 & $42 \cdot 9$ & 20 & $29 \cdot 4$ & 2 & $7 \cdot 1$ & 4 & $25 \cdot 0$ & 11 & $40 \cdot 7$ & 17 & 23.9 & 37 & $26 \cdot 6$ \\
\hline Undergraduate or above & 23 & $91 \cdot 3$ & 9 & $60 \cdot 0$ & 16 & $57 \cdot 1$ & 48 & $70 \cdot 6$ & 26 & $92 \cdot 9$ & 12 & $75 \cdot 0$ & 16 & $59 \cdot 3$ & 54 & $76 \cdot 1$ & 102 & 73.4 \\
\hline Marital status & & & & & & & & & & & & & & & & & & \\
\hline Married/cohabiting & 24 & $96 \cdot 0$ & 14 & $93 \cdot 3$ & 25 & $89 \cdot 3$ & 63 & $92 \cdot 6$ & 27 & $96 \cdot 4$ & 16 & $100 \cdot 0$ & 24 & 88. 9 & 67 & 94.4 & 130 & 93.5 \\
\hline Single & 1 & 4.0 & 1 & $6 \cdot 7$ & 3 & $10 \cdot 7$ & 5 & $7 \cdot 4$ & 1 & 3.6 & 0 & 0.0 & 3 & $11 \cdot 1$ & 4 & $5 \cdot 6$ & 9 & 6.5 \\
\hline Vegetable intake (serves/d) & & & & & & & & & & & & & & & & & & \\
\hline Mean & & & & & & & & & & 6 & & 2 & & 7 & & 9 & & \\
\hline SD & & & & & & & & & & 1 & & 6 & & 1 & & 2 & & \\
\hline Fruit intake (serves/d) & & & & & & & & & & & & & & & & & & \\
\hline Mean & & & & 7 & & & & & & 6 & & 4 & & 1 & & 1 & & \\
\hline SD & & & & 9 & & & & & & 1 & & 0 & & 2 & & 2 & & \\
\hline Infants & & & & & & & & & & & & & & & & & & \\
\hline Sex (male) & 12 & $48 \cdot 0$ & 10 & $66 \cdot 7$ & 11 & $39 \cdot 3$ & 33 & 48.5 & 16 & $57 \cdot 1$ & 11 & $68 \cdot 8$ & 13 & $48 \cdot 2$ & 40 & $56 \cdot 3$ & 73 & 52.5 \\
\hline Milk feeding method $\dagger$ & & & & & & & & & & & & & & & & & & \\
\hline Entirely breastfed & 17 & $68 \cdot 0$ & 5 & $33 \cdot 3$ & 15 & $53 \cdot 6$ & 37 & 54.4 & 15 & $53 \cdot 6$ & 6 & 37.5 & 14 & 51.9 & 35 & $49 \cdot 3$ & 72 & 51.8 \\
\hline Mixed & 5 & $20 \cdot 0$ & 10 & $66 \cdot 7$ & 10 & $35 \cdot 7$ & 25 & $36 \cdot 8$ & 11 & $39 \cdot 3$ & 10 & 62.5 & 10 & $37 \cdot 0$ & 31 & $43 \cdot 7$ & 56 & $40 \cdot 3$ \\
\hline Entirely bottle fed & 3 & $12 \cdot 0$ & 0 & 0.0 & 3 & $10 \cdot 7$ & 6 & 8.8 & 2 & $7 \cdot 1$ & 0 & 0.0 & 3 & $11 \cdot 1$ & 5 & $7 \cdot 0$ & 11 & 7.9 \\
\hline Gestational age (weeks) & & & & & & & & & & & & & & & & & & \\
\hline Mean & & & & 9 & & & & & & $\cdot 7$ & & .0 & & 5 & & 1 & & 0 \\
\hline SD & & & & & & & & & & 3 & & 9 & & 0 & & 8 & & 8 \\
\hline Birth weight (kg) & & & & & & & & & & & & & & & & & & \\
\hline Mean & & & & & & & & & & 6 & & 2 & & 1 & & 3 & & 3 \\
\hline SD & & & & & & & & & & 5 & & 4 & & 4 & & 5 & & 5 \\
\hline Age at introduction of solid f & & & & & & & & & & & & & & & & & & \\
\hline Mean & & & & 1 & & & & & & 4 & & 8 & & 0 & & 3 & & \\
\hline SD & & & & & & & & & & 5 & & 3 & & 6 & & 6 & & \\
\hline
\end{tabular}

${ }^{*}$ The variables were categorised as follows - below university: no qualifications, secondary school certificate, technical school, high school certificate, private faculty diploma; undergraduate and above: undergraduate degree, postgraduate qualification

†The variables were categorised as follows - entirely breastfed: breastfeeding exclusively; mixed: mostly breastfeeding with some bottle-feeding, equally breastfeeding and bottle-feeding, mostly bottle-feeding and some breastfeeding; entirely bottle fed: almost all bottle-feeding (only tried breastfeeding a few times), Bottle-feeding only (never tried breastfeeding). 
Table 2. First foods offered to infants by country and experimental condition

(Number of infants and percentages)

\begin{tabular}{|c|c|c|c|c|c|c|c|c|c|c|c|c|c|c|c|c|}
\hline \multirow[b]{3}{*}{ Food categories } & \multicolumn{4}{|c|}{ Countries combined } & \multicolumn{4}{|c|}{ UK } & \multicolumn{4}{|c|}{ Greece } & \multicolumn{4}{|c|}{ Portugal } \\
\hline & \multicolumn{2}{|c|}{$\begin{array}{l}\text { Control } \\
(n 68)\end{array}$} & \multicolumn{2}{|c|}{$\begin{array}{l}\text { Intervention } \\
\quad(n 71)\end{array}$} & \multicolumn{2}{|c|}{$\begin{array}{c}\text { Control } \\
(n 25)\end{array}$} & \multicolumn{2}{|c|}{$\begin{array}{l}\text { Intervention } \\
\quad(n 28)\end{array}$} & \multicolumn{2}{|c|}{$\begin{array}{l}\text { Control } \\
(n 15)\end{array}$} & \multicolumn{2}{|c|}{$\begin{array}{l}\text { Intervention } \\
\quad(n 16)\end{array}$} & \multicolumn{2}{|c|}{$\begin{array}{l}\text { Control } \\
(n 28)\end{array}$} & \multicolumn{2}{|c|}{$\begin{array}{l}\text { Intervention } \\
\quad(n 27)\end{array}$} \\
\hline & $n$ & $\%$ & $n$ & $\%$ & $n$ & $\%$ & $n$ & $\%$ & $n$ & $\%$ & $n$ & $\%$ & $n$ & $\%$ & $n$ & $\%$ \\
\hline Isolated vegetable & 10 & $14 \cdot 7$ & 60 & 84.5 & 8 & $32 \cdot 0$ & 26 & 92.9 & 1 & $6 \cdot 7$ & 16 & $100 \cdot 0$ & 1 & 3.6 & 18 & $66 \cdot 7$ \\
\hline Isolated fruit & 7 & $10 \cdot 3$ & - & - & 3 & $12 \cdot 0$ & - & - & 3 & $20 \cdot 0$ & - & - & 1 & 3.6 & - & - \\
\hline Baby rice or cereal & 31 & $45 \cdot 6$ & 7 & 9.9 & 14 & $56 \cdot 0$ & 2 & $7 \cdot 1$ & 11 & 73.3 & - & - & 6 & 21.4 & 5 & 18.5 \\
\hline Vegetable soup* & 20 & 29.4 & 4 & 5.6 & - & - & - & - & - & - & - & - & 20 & 71.4 & 4 & $14 \cdot 8$ \\
\hline
\end{tabular}

*Vegetable soups are common weaning foods in Portugal and typically include potato, olive oil and at least two different vegetables (e.g. carrot, pumpkin, onion, garlic and leek).

The results of the taste tests by experimental condition are shown in Table 3 . The mean intake of the unfamiliar vegetable purée was almost $10 \mathrm{~g}$ higher among the intervention group infants $(38.91 \mathrm{~g})$ compared to the control group (29.84 g). However, the primary analyses examining the effect of the intervention in the three countries combined ( $n$ 139) revealed no significant main effect of the intervention on vegetable intake, controlling for the effect of country $\left(F_{(1,135)}=3 \cdot 49\right.$, $P=0.064)$. Infants in the intervention group were rated by researchers as liking the unfamiliar vegetable significantly more than control infants $\left(F_{(1,135)}=4.70, P<0.032\right)$, but a similar trend observed for maternal ratings of infants' vegetable liking did not reach significance $\left(F_{(1,135)}=3 \cdot 84\right.$, $P=0.052$ ), while controlling for the effect of country in the pooled sample. No main effect of the intervention was found for either intake or liking ratings for fruit.

Separate analyses by country revealed a significant effect of the intervention on intake of the novel vegetable in the UK, with intervention infants eating on average $16 \mathrm{~g}$ more artichoke purée than control infants $(32.8 v .16 .5 \mathrm{~g} ; t(51)=3 \cdot 10$; $P=0.003$ ) (see Table 4 ). This group difference in vegetable intake represented a large effect size (Cohen's $d=0 \cdot 8)^{(13)}$. UK intervention infants were also rated as liking the purée significantly more than control infants by mothers (6.7 $v$. $4.3 ; \quad t(51)=4.51 ; \quad P<0.001)$ and researchers $(6.7 \quad v .4 .6$; $t 51)=4.37 ; P<0.001)$ separately (see Table 4). A large intervention effect size was observed for both maternal and researcher ratings of liking (Cohen's $d=1 \cdot 2$ for both).
No group differences were found between UK intervention and control infants for intake $(27.9 v .40 .7 \mathrm{~g})$ or liking ratings of the unfamiliar fruit.

In the Greek sample, mean intake in the intervention group was on average $13 \mathrm{~g}$ higher than in the control group $(36 \cdot 3 \mathrm{v}$. $23.6 \mathrm{~g}$ ), although this difference was not statistically significant. Intervention infants were also given slightly higher vegetable liking ratings in the taste test by both mothers (4.3 v.3.3) and researchers ( $4.6 v .3 .4)$ in Greece but again these differences were not significant.

In Portugal, no significant intervention effect on infants' intake of the artichoke purée was observed at follow-up, with intervention infants consuming only an average of $2 \mathrm{~g}$ more than control infants $(46.9 v$ v $45 \cdot 1 \mathrm{~g})$. Similarly, there was no effect of the intervention on mothers' or researchers' vegetable liking ratings for the Portuguese infants ( $4.6 v \cdot 5 \cdot 2$ and $4.5 v .5 \cdot 0$, respectively).

There were no significant group differences in intake or either mother's or researcher's ratings of the infants' liking of the unfamiliar fruit purée in any of the three countries (see Table 4)

\section{Discussion}

No significant main effect of the intervention on children's intake of a novel vegetable was found in the full sample. Children in the intervention group were rated by researchers as liking the unfamiliar vegetable more than the control

Table 3. Taste test: vegetable and fruit intake and liking rating by experimental condition (Mean values and standard deviations)

\begin{tabular}{|c|c|c|c|c|c|}
\hline & \multicolumn{2}{|c|}{ Control ( $n$ 68) } & \multicolumn{2}{|c|}{ Intervention ( $n 71)$} & \multirow[b]{2}{*}{$P($ ANCOVA $) \dagger$} \\
\hline & Mean & SD & Mean & SD & \\
\hline \multicolumn{6}{|l|}{ Vegetable (artichoke) } \\
\hline Intake $(\mathrm{g})$ & $29 \cdot 84$ & $30 \cdot 12$ & 38.91 & 33.65 & 0.064 \\
\hline Maternal rated liking & 4.50 & 2.63 & $5 \cdot 34$ & $2 \cdot 47$ & 0.052 \\
\hline Researcher rated liking & 4.51 & $2 \cdot 37$ & $5 \cdot 38$ & $2 \cdot 36$ & $0.032^{*}$ \\
\hline \multicolumn{6}{|l|}{ Fruit (peach) } \\
\hline Intake (g) & $64 \cdot 23$ & 65.56 & $51 \cdot 18$ & $51 \cdot 76$ & 0.211 \\
\hline Maternal rated liking & 6.57 & 2.66 & $6 \cdot 20$ & 51.76 & 0.371 \\
\hline Researcher rated liking & 6.46 & $2 \cdot 71$ & 6.07 & 2.45 & 0.327 \\
\hline
\end{tabular}

${ }^{*}$ Value was significantly different $(P<0.05)$ $\dagger$ Effect of condition controlling for country 
group, but this was not the case for maternal ratings. However, UK intervention infants ate significantly more of an unfamiliar vegetable and were rated by both mothers and researchers as liking the vegetable more than infants in the control group 1 month after the introduction of solid foods. In the Greek and Portuguese samples, there was no significant effect of the intervention on either intake or liking of an unfamiliar vegetable. However, observations of the raw data in Greece did suggest a positive trend towards higher consumption among the intervention infants.

The UK findings provide support for previous research showing repeated exposure to vegetables during complementary feeding can impact positively on infants' vegetable acceptance $e^{(22,30,31)}$ and daily changes in the variety of vegetables consumed increase acceptance of a novel food ${ }^{(17,18)}$. The differences in the outcomes observed across the three study sites may be partly explained by cultural variations in typical weaning practices in these countries. Recent research has revealed that Portuguese school children have among the highest levels of vegetable intake in Europe ${ }^{(32)}$. In addition, the Euro-Growth study, examining infant feeding practices and the introduction of complementary foods across Europe, found that fruit was the most common first food offered to infants in both Greece and the UK, while in Portugal it was cereal or vegetables ${ }^{(33)}$. This suggests that normal weaning practices in Portugal more closely resemble those advocated in the present study, potentially minimising differences between intervention and control groups. The observation that over $70 \%$ of the Portuguese control infants in the present study were given vegetable-based soups as their first food supports this assertion. In contrast, only $32 \%$ of the UK control infants and just $7 \%$ of the Greek control infants received vegetables as their first foods. Instead, baby rice or cereals were the most common first foods consumed by control infants in the UK (56\%) and Greece (73\%). This is also reflected in the raw intake data from the taste test in which Portuguese control infants ate more of the unfamiliar vegetable purée than UK or Greek intervention infants.

No group differences in fruit intake or liking were observed in the taste test in any of the three countries. This suggests that introducing single vegetables as first foods, and not offering fruit for the first $15 \mathrm{~d}$ does not reduce fruit preference in young infants. This is reassuring, but unsurprising given infants' innate preferences for sweet tastes ${ }^{(34,35)}$. The finding that vegetable exposure does not affect fruit acceptance also supports a recent study that found infants who had been exposed to $5 \mathrm{~d}$ of rice flour porridge, followed by $19 \mathrm{~d}$ of vegetables, ate on average the same amount of a novel fruit immediately post-intervention as infants who had no exposure yet to either fruits or vegetables and had only received $5 \mathrm{~d}$ of rice flour porridge ${ }^{(30)}$.

Alternative explanations for the group differences in novel vegetable acceptance observed for UK infants should be acknowledged. It is possible that the intervention infants received less energy as a result of consuming vegetables only for the first $15 \mathrm{~d}$ of weaning and were therefore hungrier than control infants during this period. However, there is no clear reason why this phenomenon should be unique to UK 
infants. In addition, first solid foods are 'complementary' to the continuation of milk feeding and most infants continue to consume a large proportion of their energy via breast or formula milk during this early weaning period, particularly if solids are introduced prior to 6 months as was common in the present study. As the intervention feeding plan lasted $15 \mathrm{~d}$ and the taste tests were conducted 1 month after the introduction of solids, it is particularly unlikely that intervention infants were systematically hungrier than control infants at the time of the taste tests.

Necessary variations in the study procedures of the participating countries are likely to have impacted on results. In Portugal, researchers had to acquire permission from the infants' paediatricians or general practitioner in order to conduct the study and in a proportion of cases the advice was delivered by health professionals rather than researchers. Although acceptance was generally high, all health professionals did not comply fully with the intervention even after agreeing to participate. Consequently, fidelity of, and adherence to, the intervention may have been undermined. There is some evidence of lower compliance among Portuguese participants - only $67 \%$ of the intervention mothers gave their infants an isolated vegetable as their first food as requested, compared to $93 \%$ in the UK and $100 \%$ in Greece. In addition, fewer Portuguese intervention parents (63\%, compared to $100 \%$ in the UK and Greece) returned completed study charts, suggesting lower compliance with the intervention procedure. There is a need to repeat this study in a larger sample within countries where vegetables are not already common first foods, and further research would benefit from exploring differences in outcome when advice is delivered by health professionals compared to researchers. A further limitation of this study is that while mothers were unaware of the study hypotheses, neither they nor researchers could be 'blinded' to treatment, which may have influenced preference ratings in the taste tests. However, the ecological validity of the experiment; the fact it was implemented by mothers themselves in the home is a strength, as is the randomised study design and inclusion of a no-treatment control.

The intervention was received positively by parents who particularly welcomed the simple, prescriptive and unambiguous nature of the instructions at an often anxiety-provoking stage of infant development. UK intervention infants showed increased intake and liking of an unfamiliar vegetable in the short term but this was not true in Portugal where vegetables are commonly given as first foods. It appears that repeated exposure to a variety of vegetables at weaning may work to increase vegetable acceptance in the short term in countries where vegetables are not typically provided as first foods. However, the longer-term impact of the intervention remains to be explored. This intervention is straightforward and would be easy to disseminate to mothers during an infants' first months when parents are in frequent contact with health professionals and actively seeking advice about weaning.

\section{Acknowledgements}

The authors would like to thank the families who participated in the study and the healthcare providers and staff who assisted with their recruitment.

This research is supported by European Community's Seventh Framework Programme (FP7/2007-2013) under the grant agreement no. 245012-HabEat. The purées offered to participants in this study and the artichoke and peach purées used as a test food were donated by Danone Nutricia Research. The funders had no role in the design, analysis or writing of this article.

None of the authors reported a conflict of interest.

The authors' contributions are as follows: L. C., C. L., P. M., Y. M. and J. W. designed the research; A. F., G. M., C. L., A. O. and C. M. conducted the research; A. F., A. O., C. M. and R. B. analysed the data; A. F., L. C., G. M., C. L., R. B., A. O., C. M., G. M. and J. W. wrote the manuscript; A. F. had primary responsibility for the final content of the manuscript; and all authors read and approved the final manuscript.

\section{References}

1. Gallaway MS, Jago R, Baranowski T, et al. (2007) Psychosocial and demographic predictors of fruit, juice and vegetable consumption among 11-14-year-old Boy Scouts. Public Health Nutr 10, 1508-1514.

2. Resnicow K, Davis-Hearn M, Smith M, et al. (1997) Socialcognitive predictors of fruit and vegetable intake in children. Health Psychol 16, 272-276.

3. Beauchamp GK \& Mennella JA (2009) Early flavor learning and its impact on later feeding behavior. $J$ Pediatr Gastr Nutr 48, S25-S30.

4. Wardle J, Cooke LJ, Gibson EL, et al. (2003) Increasing children's acceptance of vegetables; a randomized trial of parent-led exposure. Appetite 40, 155-162.

5. Wardle J, Herrera ML, Cooke L, et al. (2003) Modifying children's food preferences: the effects of exposure and reward on acceptance of an unfamiliar vegetable. Eur J Clin Nutr $\mathbf{5 7}$, 341-348.

6. Cooke LJ (2007) The importance of exposure for healthy eating in childhood: a review. J Hum Nutr Diet 20, 294-301.

7. Birch LL \& Marlin DW (1982) I dont like it - I never tried it effects of exposure on 2-year-old childrens food preferences. Appetite 3, 353-360.

8. Caton SJ, Ahern SM, Remy E, et al. (2012) Repetition counts: repeated exposure increases intake of a novel vegetable in UK pre-school children compared to flavour-flavour and flavour-nutrient learning. Br J Nutr 109, 2089-2097.

9. Sullivan SA \& Birch LL (1990) Pass the sugar, pass the salt experience dictates preference. Dev Psychol 26, 546-551.

10. Liem DG \& de Graaf C (2004) Sweet and sour preferences in young children and adults: role of repeated exposure. Physiol Behav 83, 421-429.

11. Harris G, Thomas A \& Booth DA (1990) Development of salt taste in infancy. Dev Psychol 26, 534-538.

12. Birch LL, Gunder L, Grimm-Thomas K, et al. (1983) Infants' consumption of a new food enhances acceptance of similar foods. Appetite 30, 283-295.

13. Coulthard H, Harris G \& Emmett P (2009) Delayed introduction of lumpy foods to children during the complementary feeding period affects child's food acceptance and feeding at 7 years of age. Matern Child Nutr 5, 75-85. 
14. Birch LL (1998) Development of food acceptance patterns in the first years of life. Proc Nutr Soc 57, 617-624.

15. Lien N, Lytle LA \& Klepp KI (2001) Stability in consumption of fruit, vegetables, and sugary foods in a cohort from age 14 to age 21. Prev Med 33, 217-226.

16. Skinner JD, Carruth BR, Wendy B, et al. (2002) Children's food preferences: a longitudinal analysis. J Am Diet Assoc 102, 1638-1647.

17. Gerrish CJ \& Mennella JA (2001) Flavor variety enhances food acceptance in formula-fed infants. Am J Clin Nutr $\mathbf{7 3}$, 1080-1085.

18. Maier AS, Chabanet C, Schaal B, et al. (2008) Breastfeeding and experience with variety early in weaning increase infants' acceptance of new foods for up to two months. Clin Nutr 27, 849-857.

19. Mennella JA, Nicklaus S, Jagolino AL, et al. (2008) Variety is the spice of life: strategies for promoting fruit and vegetable acceptance during infancy. Physiol Behav 94, 29-38.

20. Skinner JD, Carruth BR, Bounds W, et al. (2002) Do foodrelated experiences in the first 2 years of life predict dietary variety in school-aged children? J Nutr Educ Behav 34, 310-315.

21. Cooke LJ, Wardle J, Gibson E, et al. (2004) Demographic, familial and trait predictors of fruit and vegetable consumption by pre-school children. Pub Health Nutr 7, 295-302.

22. Maier A, Chabanet C, Schaal B, et al. (2007) Effects of repeated exposure on acceptance of initially disliked vegetables in 7-month old infants. Food Qual Prefer 18, 1023-1032.

23. Mennella JA \& Trabulsi JC (2012) Complementary foods and flavor experiences: setting the foundation. Ann Nutr Metab 60, 40-50.

24. Cohen J (1998) Statistical Power Analysis for the Behavioral Sciences, 2nd ed. London: Erlbaum Associates.
25. Mennella JA, Jagnow CP \& Beauchamp GK (2001) Prenatal and postnatal flavor learning by human infants. Pediatrics 107, E88.

26. Mennella JA (2009) Flavour programming during breastfeeding. Adv Exp Med Biol 639, 113-120.

27. Guerra A, Rêgo C, Silva D, et al. (2012) Alimentação e nutrição do lactente (Feeding and infant nutrition). Acta Pediatr Port 43, S17-S40.

28. Hausner H, Olsen A \& Moller P (2012) Mere exposure and flavour-flavour learning increase 2-3 year-old children's acceptance of a novel vegetable. Appetite 58, 1152-1159.

29. Forestell CA \& Mennella JA (2007) Early determinants of fruit and vegetable acceptance. Pediatrics 120, 1247-1254.

30. Barends C, de Vries J, Mojet J, et al. (2013) Effects of repeated exposure to either vegetables or fruits on infant's vegetable and fruit acceptance at the beginning of weaning. Food Qual Prefer 29, 157-165.

31. Sullivan SA \& Birch LL (1994) Infant dietary experience and acceptance of solid foods. Pediatrics 93, 271-277.

32. Yngve A, Wolf A, Poortvliet E, et al. (2005) Fruit and vegetable intake in a sample of 11 -year-old children in 9 European countries: The Pro Children Cross-Sectional Survey. Ann Nutr Metab 49, 236-245.

33. Freeman V, van't Hof M \& Haschke F (2000) Patterns of milk and food intake in infants from birth to age 36 months: the Euro-Growth Study. J Pediatr Gastroenterol Nutr 31, S76-S85.

34. Beauchamp GK \& Moran M (1982) Dietary experience and sweet taste preference in human infants. Appetite 3, 139-152.

35. Ventura AK \& Mennella JA (2011) Innate and learned preferences for sweet taste during childhood. Curr Opin Clin Nutr Metab Care 14, 379-384. 